\title{
O USO DAS TECNOLOGIAS NO ENSINO DA LÍNGUA PORTUGUESA
}

\author{
Shigeaki Ueki Alves da Paixão \\ Marcos Antonio Braga de Freitas
}

\section{RESUMO}

A pesquisa realizada destaca a importância do uso das tecnologias como recurso didático no ensino de Língua Portuguesa $\mathrm{O}$ uso das tecnologias na sala de aula está na ordem do dia, não se pode ignorar os benefícios e a importância das mídias para melhorar e tornar mais interessante o ambiente escolar, dessa maneira o tema é de vital importância e atual, o uso do computador e o acesso a internet é uma necessidade e obrigatoriedade para a melhoria da qualidade de ensino. A escola, professores e alunos devem está em harmonia com a sociedade global. Portanto, o domínio e a apropriação das mídias é uma necessidade a ser atendida para o aperfeiçoamento da instituição escolar. a melhoria da qualidade de ensino. No que diz respeito ao ensino da Língua Portuguesa vai proporcionar a melhoria e ampliação da produção textual e leituras alternativas para que os alunos saiam da rotina da sala de aula e consigam se familiarizar com os recursos tecnológicos. Essa é a preocupação principal deste trabalho.

\section{PALAVRAS-CHAVE}

Ensino; tecnologias; metodologias.

\section{INTRODUÇÃO}

O presente artigo visa fazer uma reflexão sobre o uso das novas tecnologias como recurso pedagógico para o ensino da língua portuguesa, tornando assim o aprendizado muito mais interessante, estimulante e motivador, incentivando a leitura e a produção textual, fazendo com que o processo ensino-aprendizagem ultrapasse as barreiras dos livros didáticos, apostilas e sala de aula. Esse grande desafio se faz cada vez mais necessário no processo educacional e em nosso cotidiano, que é integrar as mídias e tecnologias no currículo escolar, tendo sido desenvolvimento e apresentado durante a etapa do processo de formação em nível de especialização em metodologia do ensino de língua portuguesa e estrangeira.

O trabalho destaca a importância do uso e da apropriação das tecnologias no ensino da Língua Portuguesa, trata do primeiro momento da questão da leitura e produção textual, em seguida discute a questão do papel do professor nesse processo de

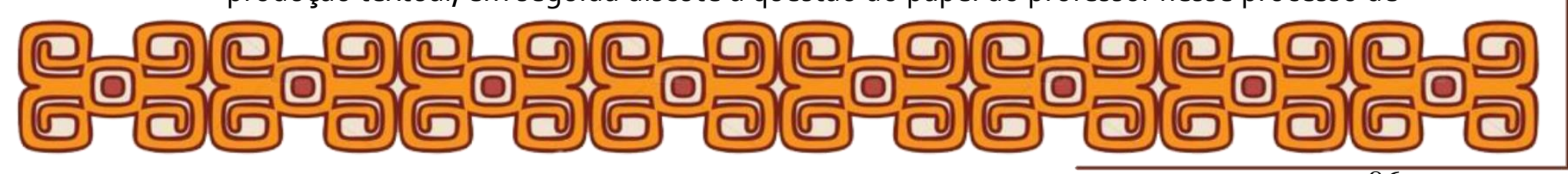




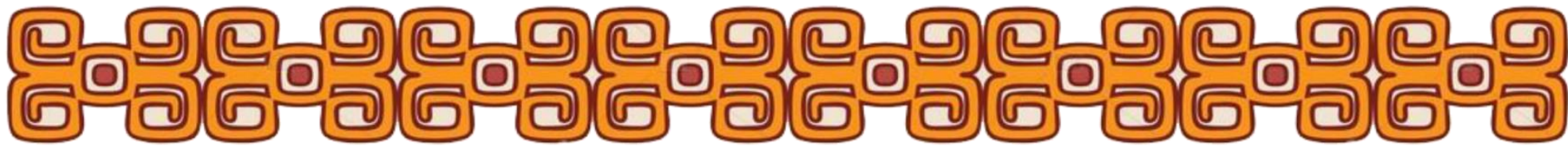

domínio e exploração dos recursos tecnológicos em sala de aula, finalmente, na última parte volta a reafirmar a importância do uso das tecnologias no ensino da Língua Portuguesa, comentando também sobre a questão da formação dos professores para o uso de novos recursos metodológicos, no sentido de tornar as aulas mais dinâmicas e motivadoras para ampliar o gosto pela leitura e produção textual.

As transformações sociais e econômicas mudaram a forma como as pessoas se comunicam e se relacionam uns com os outro, a globalização tornou o mundo sem fronteiras e as mídias e tecnologias estão relacionadas com tais transformações.

Neste contexto é importante, portanto, considerar essas transformações no ato de ensinar, e no ensino da língua portuguesa então, é fundamental o uso de todos os recursos possíveis para melhor transmitir e motivar o aluno sobre o que está se tentando ensinar.

Hoje a sociedade demanda por novas competências para aprender, ensinar, trabalhar e de se relacionar com as demais pessoas. Esta pesquisa caracteriza-se como qualitativa, porque possibilitou a interação entre professor e aluno. O procedimento metodológico para a realização deste trabalho consistiu também no levantamento bibliográfico sobre as mídias e a importância do ensino da língua portuguesa.

\section{A QUESTÃO DA LEITURA NO BRASIL}

O grande desafio dos professores das séries iniciais do Ensino Fundamental é despertar o interesse dos educandos pela leitura, uma quantidade relevante de alunos que chegam no final do quinto ano (antiga quarta série) não estão devidamente alfabetizados, apresentando muita dificuldade de produção textual, visto que não tem o hábito da leitura, por consequência tem pouco conhecimento.

Esse problema requer um processo de mudanças no trabalho pedagógico, para isso se faz necessária a participação efetiva da escola, do professor, dos pais e do próprio aluno e a inserção dos recursos tecnológicos da informática na educação escolar, pois isso pode contribuir para a melhoria das condições de acesso à informação, minimiza

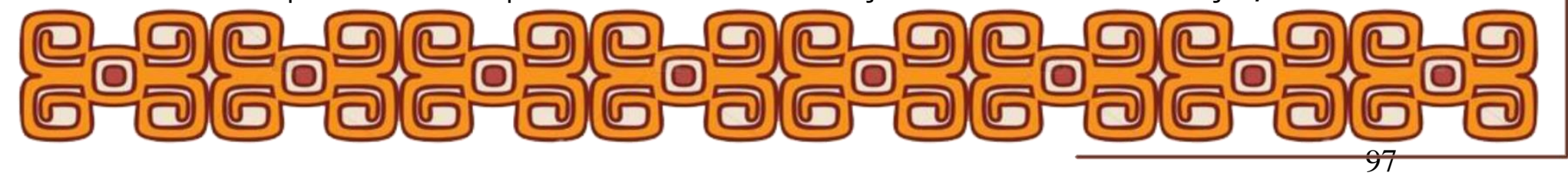




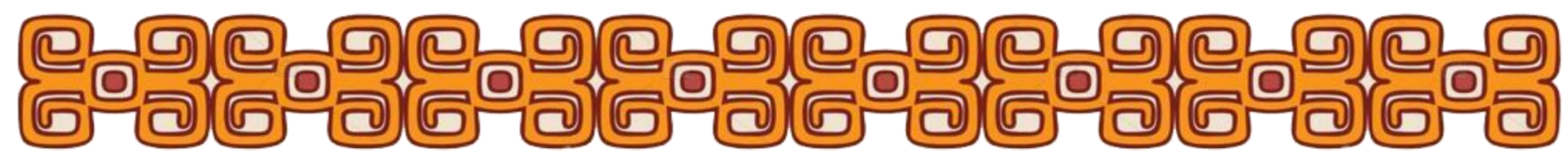

restrições relacionadas ao tempo e ao espaço e permite agilizar a comunicação entre professores, alunos e instituições.

Além disso, torna-se possível trabalhar com softwares específicos para cada disciplina (HIGINO, p. 29), os softwares educativos estimulam o interesse de aprendizagem do educando, não só nas diversas disciplinas, mas no ato de leitura e possibilitam uma série de acervos de obras literárias, ao passo que as bibliotecas ou as salas de leitura deixam a desejar por falta de renovação dessas obras.

A escola do século XXI possui laboratório de informática, e com isso cria oportunidade para o aluno fazer leituras virtuais o que torna, com certeza, a leitura realmente prazerosa e ao alcance de boa parcela da sociedade. A leitura virtual é dinâmica por se tratar de ferramenta hipertextual, possibilita ao leitor interação com o autor da obra e interação com outros leitores.

Observando-se hoje o cotidiano das salas de aula percebe-se a ausência do hábito de leitura por parte dos alunos, e se torna o grande desafio dos professores, contando então com a utilização da internet como mídia. Compartilhando do pensamento de que o educando estará envolvido diretamente na escolha do tipo de leitura, que dessa forma a leitura se tornará prazerosa, afinal o principal autor nesse mundo de leitura é o aluno que deve ter em mente a importância da leitura para sua formação como cidadão crítico. É saber ler nas entrelinhas do texto o que o autor pretende transmitir, como nos diz Lajolo (1993):

Ler não é decifrar, como num jogo de adivinhação, o sentido de um texto. É a partir de um texto, ser capaz de atribuir significação, conseguir relacioná-lo a todos os outros textos significativos para cada um, reconhecer nele o tipo de leitura que seu autor pretendia e, dono da própria vontade, entregar-se ou rebelar-se contra ela, propondo outra não prevista. (Lajolo, 1993, p. 59).

É importante, além da leitura, interpretar o que se lê, de maneira a criticá-lo para que se abra uma discussão a cerca do tema em questão. Não é numa simples leitura rápida que se interpreta um texto. São necessárias várias leituras e diferentes gêneros literários para que se possa redigir uma crítica, dessa forma o leitor interage com o texto

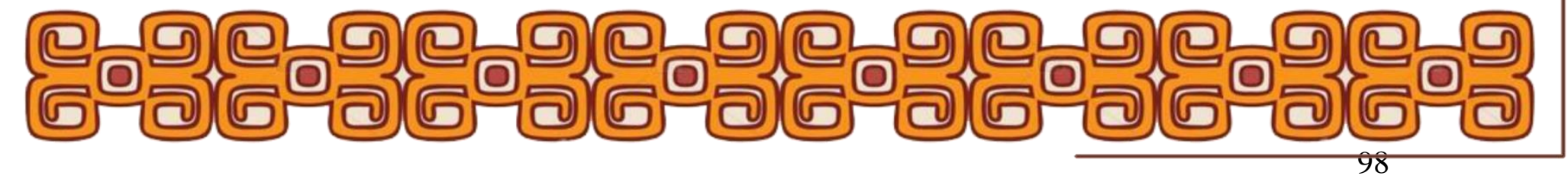




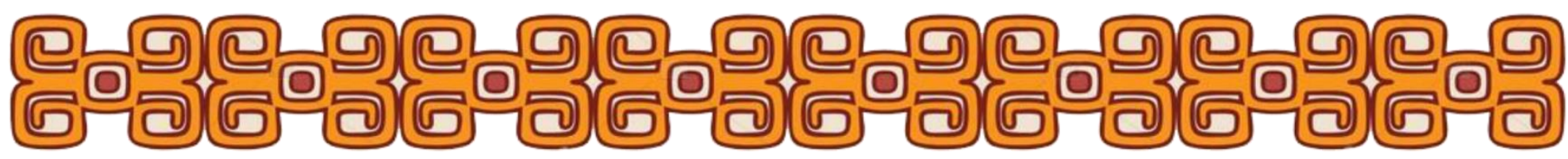

interrogando-o, criticando-o e construindo significado a partir do texto. Em se falando em leitor crítico, que constrói significado do texto, o leitor acrítico faz apenas uma leitura artificial extraindo do texto informação fragmentada.

A introdução de mídias em educação, como a utilização da internet representa, na atualidade, uma ferramenta importante onde o professor pode utilizá-la na sala de aula, com o propósito de possibilitar o acesso à leitura de forma mais prazerosa e eficaz. Isto significa que o professor poderá utilizar essa ferramenta articulada a uma proposta pedagógica de leitura tradicional.

Esse instrumento tecnológico deve ser muito bem aproveitado e explorado pelo professor de Língua Portuguesa, para isso existem duas questões a considerar: a capacitação do professor e a adequação da escola com laboratórios de informática com acesso a internet, possibilitando ao professor(a) uma cobrança maior de seus alunos e mais empenho nas leituras de livros, jornais, revistas e para que os alunos se tornem leitores críticos com essa utilização de mídias.

\section{O PROFESSOR E O USO DAS MÍDIAS NO PROCESSO DE LEITURA}

Atualmente o professor dispõe de diversos recursos tecnológicos (computador, data show, Internet, Histórias em Quadrinhos - HQs entre outros) para melhorar sua comunicação com os alunos, de introduzir conteúdos. O docente pode procurar a melhor forma de integrar as mais diversas tecnologias e metodologias, para tanto é necessário que o mesmo tenha o domínio, o conhecimento tecnológico para que ocorra uma mudança qualitativa no processo ensino aprendizagem.

A sociedade hoje busca por novas formas de aprender e ensinar e a relação professor-aluno é muito importantes, pois os alunos sabem quando o professor gosta de ensinar e, principalmente, quando gosta deles, tendo acesso a programas que permitem

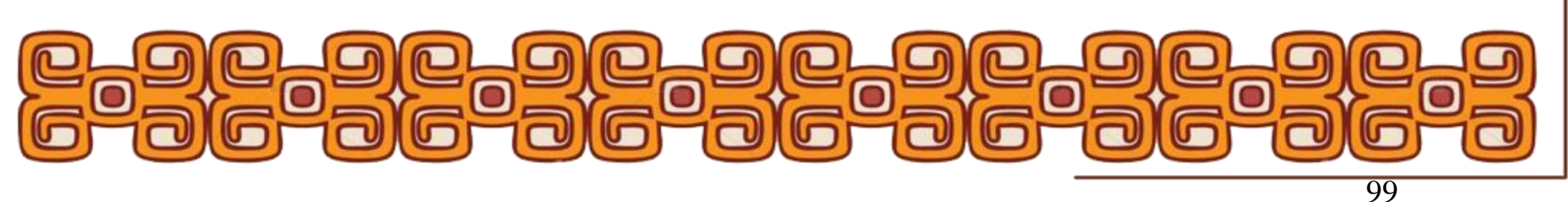




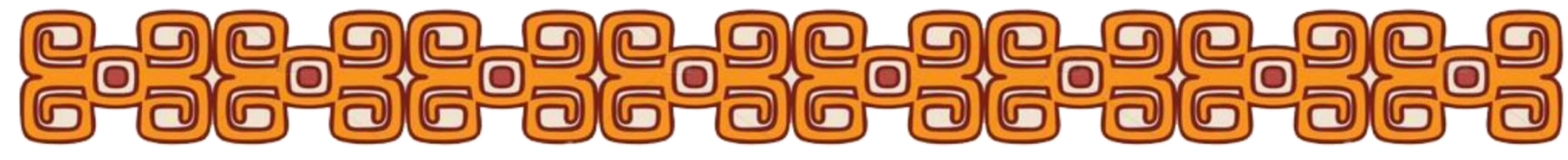

a criação de ambientes virtuais e que facilitam a interação entre professor e aluno.

O aluno motivado torna-se mais participativo e aprender de forma colaborativa é bem mais interessante, porém, é importante esclarecer que as tecnologias por si só não faz muita diferença, depende muito do uso que se faz delas, e também de uma série de situações, por exemplo, ter laboratórios a disposição, ter uma política de formação de profissionais para atuar nesses laboratórios, além de outras questões referentes a formação e valorização dos professores.

Autores como Vergueiro (2007), Calazans (2005) já defendem a importância dos quadrinhos como facilitador do acesso à literatura e do processo ensino aprendizagem dentro de sala de aula. Segundo Oliveira (2005)

\begin{abstract}
Já cresceu o reconhecimento da $\mathrm{HO}$ como recurso pedagógico, porém, na escola, instituição que homologa o uso dos quadrinhos como ferramenta de ensino e aprendizagem, a concepção que prevalece é aquela que vê nos quadrinhos apenas um recurso auxiliar para aprender, não reconhecendo neles o seu diálogo com o literário. Há uma carência sobre o quadrinho e as possibilidades comunicativas que ele oferece. O quadrinho apresenta novas formas de criar textos e de leitura. É uma arte que, ao contrário do que se pensa, precisa ser apreendida e compreendida. O quadrinho é um meio que pode servir a muitos fins, como despertar um olhar criativo, o raciocínio rápido, a concatenação de idéias, o domínio de técnicas de composição e da exploração visual. Os quadrinhos podem ser um meio de formação de leitores, não passivos, meros receptores, mas ativos, colaboradores importantes na leitura e na construção de novos textos.
\end{abstract}

Portanto, o professor deve procurar meios que levem os alunos a se tornarem críticos em relação a eles, desta forma o educador torna-se o estimulador, o parceiro do processo ensino aprendizagem e deixa de ser simples transmissor do conhecimento. E as tecnologias estimulam o educador a criar projetos pedagógicos utilizando as mais diversas mídias e tecnologias proporcionando maior interatividade, essa comunicação se dá através do e-mail, do blog, da internet, no chat, na sala de aula ajudando o aluno na construção de sua identidade, na vida pessoal e profissional, alias todos estamos reaprendendo a aprender, a ensinar e a nos comunicar. Para tanto, o professor deve buscar equilíbrio entre as tecnologias e conhecimento curricular e suas potencialidades

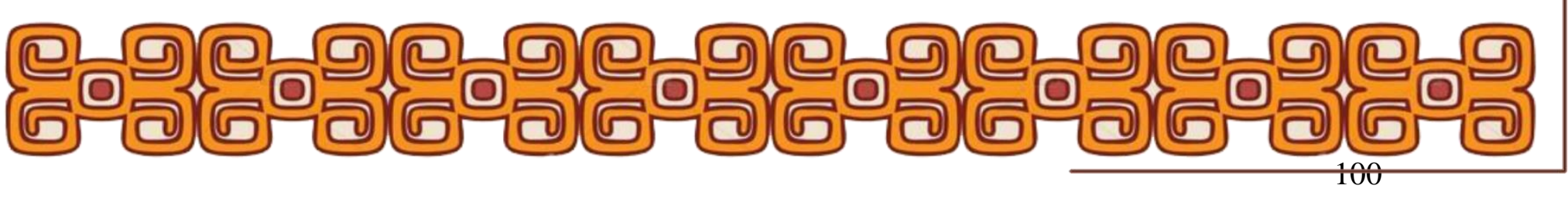




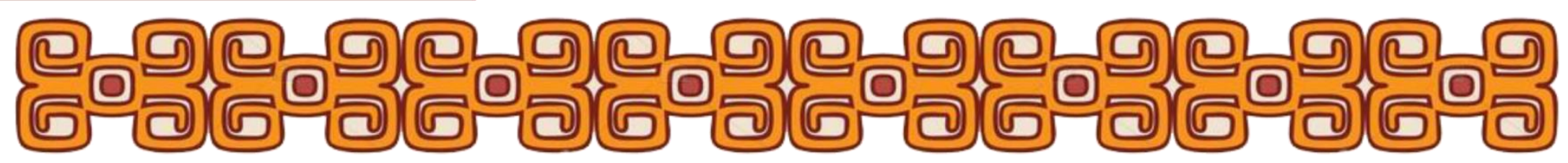

educacionais.

Somos educados em todos os momentos e espaços, somos capazes de extrair informações e experiências de qualquer situação para ampliar nosso conhecimento e nossa visão de mundo.

Na educação deve ter o equilíbrio entre flexibilidade e organização. A flexibilidade para nos adaptarmos as diferenças individuais de cada um seja ela cultural ou pessoal, obedecendo ao ritmo de aprendizagem que cada um individua possui. Organização para saber programar o tempo e o conteúdo de forma que esteja adequado as necessidades e a realidade do cotidiano de cada aluno e também com os imprevistos que podem ocorrer de uma sala de aula.

O aluno depende cada vez menos do professor para adquirir a informação, pois basta acessar a internet que dispomos de informações rápidas, precisas e atuais com imagens e resumos práticos e bastante atraentes. Cabe ao professor ensinar esses alunos a relacionar, interpretar e textualizar essas informações para melhorar o seu próprio ensino e aprendizagem.

Acompanhar atentamente as mudanças na educação é um fator fundamental que busca adquirir tudo de forma pratica e rápido. O professor é um mediado do progresso no processo de aprender, ele deixou de ser o dono do saber o aluno já traz consigo o conhecimento. Manter o equilíbrio entre as expectativas sociais, individuais e as do grupo de forma flexível facilitando a organização e adaptação da trajetória educacional de cada aluno a postura do professor é fundamental para o sucesso do processo de ensino e aprendizagem.

Numa sociedade tecnológica e pós-moderna é necessário inovar as metodologias e técnicas de ensinar, é preciso a busca de formas de aproximação dos alunos, respeitando a condição em busca de formas de aproximação dos alunos, respeitando a condição humana de cada um, em uma sala de aula existem alunos que já estão prontos para aprender, mas que também precisam de estímulos.

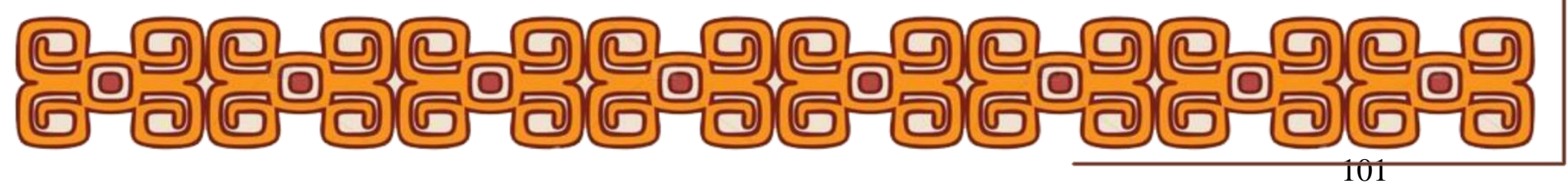




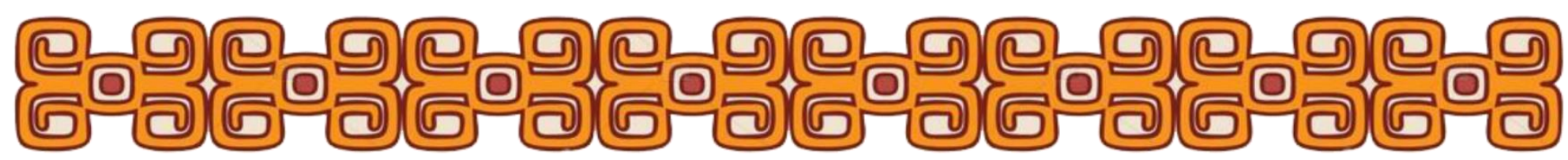

Nesse processo de mudança depende também do aluno, através de uma comunicação aberta, mas deve se considerar que o aluno de hoje tem acesso a videogames, internet e uma gama de informações que em décadas anteriores não era possível, a relação de professores e alunos precisa ser mais aberta. Através das Tecnologias da Comunicação e Informação (TICs) é possível obter uma relação mais aberta e uma interação comunicativa, participativa e inovadora.

A internet é uma ferramenta fantástica que permite que o estudar vá além da sala de aula, ou seja, em casa o aluno pode continuar estudando. A comunicação virtual junto com o presencial é um perfeito estimulante para o aprendizado.

Dentro deste contexto Segundo (Pais, 2005, p. 56), o uso pedagógico do computador deve esboçar uma concepção de criatividade que seja, no mínimo, compatível com a potencialidade dos vários recursos que essa tecnologia oferece. Criar conhecimentos com o apoio de recursos digitais parece ser uma ordem de desafios para a educação contemporânea.

Com o advento da rede mundial de computadores, e onde um telefone celular dá acesso a informações simultâneas em qualquer lugar do planeta, não se pode ignorar que a escola, com todas as pessoas envolvidas no processo de socialização e da educação como processo formal, é vital para aumentar a credibilidade e a capacitar da escola de oferecer um ensino de qualidade sobre todos os aspectos.

\section{AS NOVAS TECNOLOGIAS NO ENSINO DA LÍNGUA PORTUGUESA}

É importante que o professor de Língua Portuguesa, em qualquer nível de ensino, deve se adequar a essa sociedade tecnológica, mas também os cursos de formação de professores devem preparar melhor para esse novo contexto, no currículo dos cursos de Letras devem atender as necessidades das tecnologias de informação.

O processo de globalização e a nova base tecnológica da sociedade são frutos de transformações produzidas no próprio sistema capitalista e por ele utilizadas (FRIGOTTO, 1992; VILLA, 1995). A tecnologia deve ser entendida como resultado e

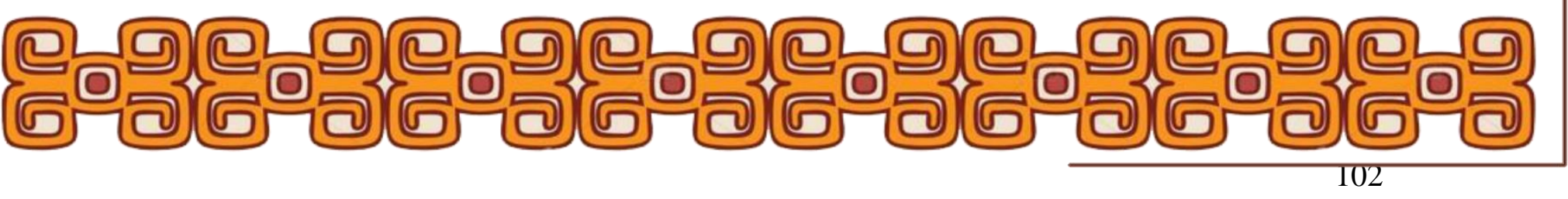




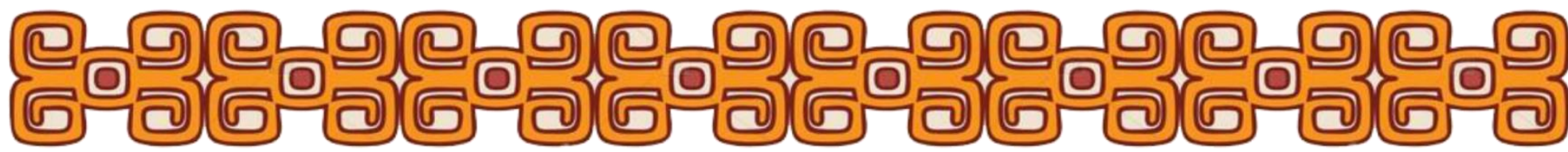

expressão das relações sociais, e as consequências desse processo tecnológico só podem ser entendidas no contexto dessas relações. Essa nova ordem social interfere diretamente no processo formal de ensino, a escola, instituição responsável por esse processo precisa se apropriar das novas tecnologias e utilizá-las como recurso metodológico nas disciplinas em sala de aula.

Nos chamados países de e se trata a educação de maneira mais respeitosa, as transformações mundiais que afetam a economia desde a década de 70, surgindo uma nova estratégia das empresas se organizarem em seus processos de produção e requalificação de mão-de-obra, essas transformações afetam e interferem no modelo de educação.

O desenvolvimento das novas tecnologias e sua inserção no ambiente escolar é uma realidade e uma necessidade iminente que deve ser observada pelos educadores comprometidos com a efetiva aprendizagem dos educandos. O papel da escola e dos professores então, é fundamental, a escola como instituição formadora do cidadão deve acompanhar esse desenvolvimento tecnológico, visto que, os níveis de qualificação para ingresso no mercado de trabalho são cada vez mais elevados.

A mídia, de uma forma geral, tem desempenhando papel fundamental no universo das imagens e informações que nos rodeiam e, tal universo não está desvinculado da escola. É um desafio muito grande para o professor da atualidade, estabelecer conexões entre Educação e Tecnologias em seu local de trabalho.

O professor, na atual conjuntura, deve, portanto, ter domínio não só de ensinar a língua vernácula, ele deve ter conhecimentos além dos profissionais com conhecimentos em matérias específicas e sim seres humanos capazes, seguros, aptos para pesquisar, questionar, viver em grupo, em suma, para o exercício pleno da cidadania, para que possa contribuir mais intensamente na formação dos alunos.

O professor de língua portuguesa tem a grande responsabilidade de estimular os alunos a despertar para a leitura, mas agora utilizando as mídias em sala de aula terá uma grande possibilidade de sucesso, claro que para isso a escola, como instituição educadora, deve oferecer as condições necessárias para que o professor possa realmente

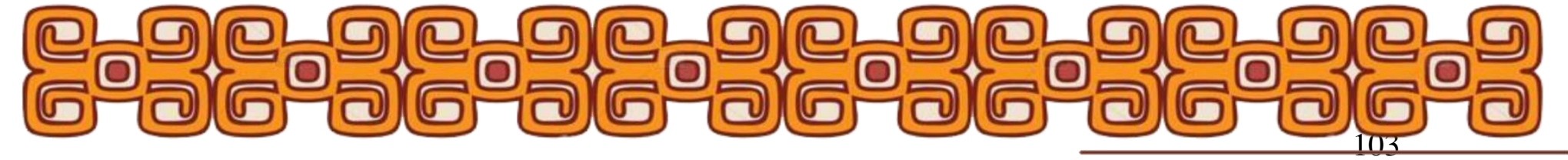




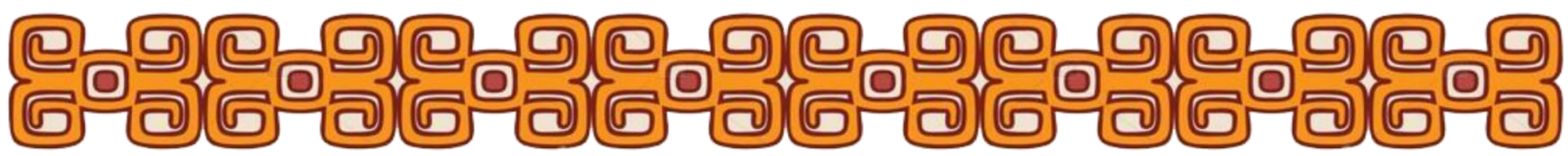

fazer esse trabalho, ele próprio precisa se capacitar melhor para utilizar corretamente as mídias em suas aulas.

É importante ressaltar que, embora esteja em sua fase inicial, entende-se que esse estudo mostra-se relevante aos estudos da linguagem, pois procura investigar a aplicabilidade do trabalho com blog no ensino de Língua Portuguesa por exemplo, o aluno vai precisar produzir textos para postar, além disso, a comunicação só é possível com o domínio da leitura e da escrita.

O educador precisa compreender que há uma infinidade de opções metodológicas e as mídias tecnológicas se constituem uma opção a mais na sua trajetória pedagógica. É preciso descobrir a maneira mais adequada de integrar o humano e o tecnológico, de ampliar as possibilidades, de organizar a comunicação com os alunos.

O grande desafio do professor é o de mediar a cultura midiática no âmbito escolar transformando esse local num espaço de inclusão social onde todos tenham o mesmo acesso às informações, aos meios de comunicação, à igualdade de oportunidades, uma vez que se busca um ensino de qualidade que prime integrar não apenas as mídias tecnológicas e a escola, mas também, e, principalmente todas as dimensões do ser humano, sejam no aspecto ético, intelectual, emocional e/ou tecnológico que permeiem entre o pessoal e o social, é necessário mudar, é, portanto, preciso mediar, indicar caminhos que facilitem a aprendizagem, que pode propiciar a construção e aplicação do conhecimento na e para a sociedade.

Há muito que fazer na questão de leitura. É necessário que todos estejam envolvidos em campanhas para chamar a atenção dos alunos na importância do ato de ler. Que sem leitura seu discurso é pobre, sua mente não se desenvolve, não há como argumentar qualquer tema.

Não importa de como se escreva, mas o que se escreve do texto, aonde se quer chegar com esse texto, que objetivo se quer alcançar e saber que quando se ler um texto encontramos vários significados nas suas entrelinhas. Para atingir os conhecimentos se faz necessária leitura de vários gêneros literários, para que haja diversidades de texto e

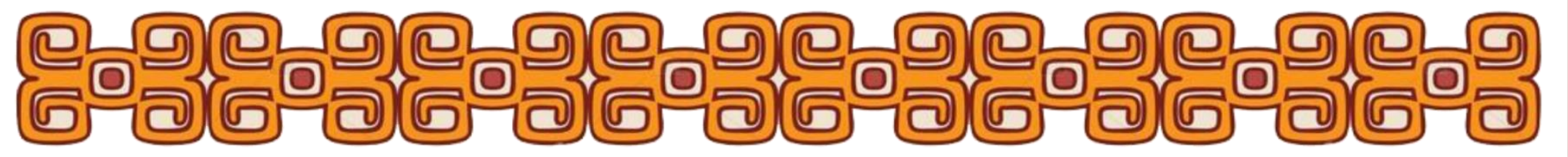




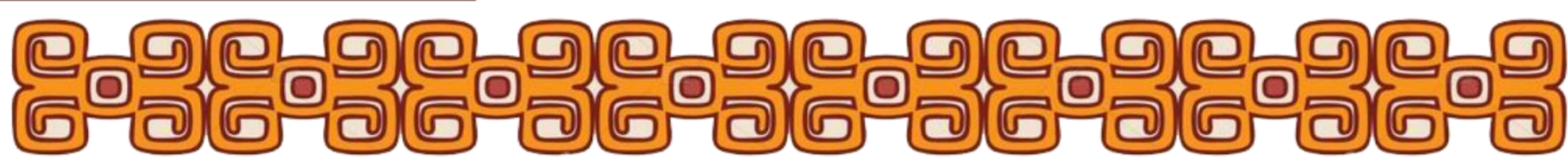

com isso o aluno saiba se comunicar entre si.

Os Parâmetros Curriculares Nacionais (PCNs, 1997) diz que: a leitura é um processo no qual o leitor realiza um trabalho de construção do significado do texto, a partir dos seus objetivos, do seu conhecimento sobre o assunto, sobre o autor, de tudo o que sabe sobre a língua: características do gênero, do portador, do sistema de escrita. Não se trata simplesmente de extrair informação da escrita decodificando-a letra por letra, palavra por palavra. Trata-se de uma atividade que implica, necessariamente, compreensão na qual os sentidos começam a ser construído antes da leitura propriamente dita. Parâmetros Curriculares Nacionais (PCNs, 1997, p. 53).

É realmente necessário que o leitor já tenha um pré-conhecimento de sua vida fora da escola, no seu dia a dia para que possa desenvolver bons textos e compreenda que a leitura implica conhecimentos.

Uma vez que, nos dias de hoje, temos as mais diversas tecnologias digitais (computadores com softwares educativos, vídeos, televisão, TV Pendrive, mesas pedagógicas, rádio e o cinema) que possibilitam às crianças utilizarem sua criatividade e imaginação para desenvolver suas habilidades e competências.

Segundo (Pais, 2005, p. 56), o uso pedagógico do computador deve esboçar uma concepção de criatividade que seja, no mínimo, compatível com a potencialidade dos vários recursos que essa tecnologia oferece. Criar conhecimentos com o apoio de recursos digitais parece ser uma ordem de desafios para a educação contemporânea.

\section{CONSIDERAÇÕES FINAIS}

Com base nesta pesquisa bibliográfica, fica clara a importância do uso das tecnologias como recurso metodológico nas aulas de Língua Portuguesa, o contexto da sociedade mundial de globalização e tecnologia, os profissionais da educação devem se apropriar desses recursos, se não tiveram isso na sua formação, devem se capacitar para tal.

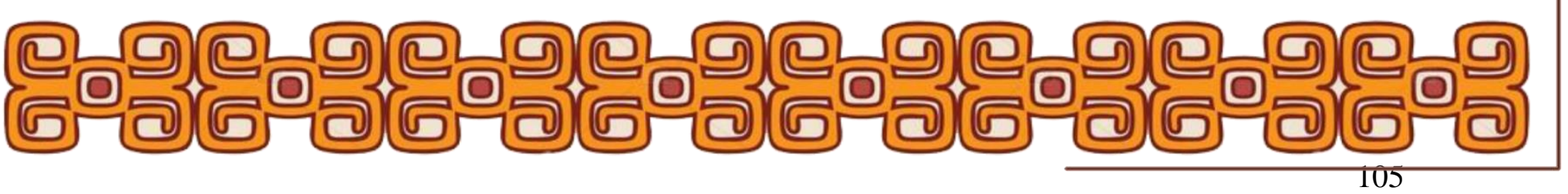




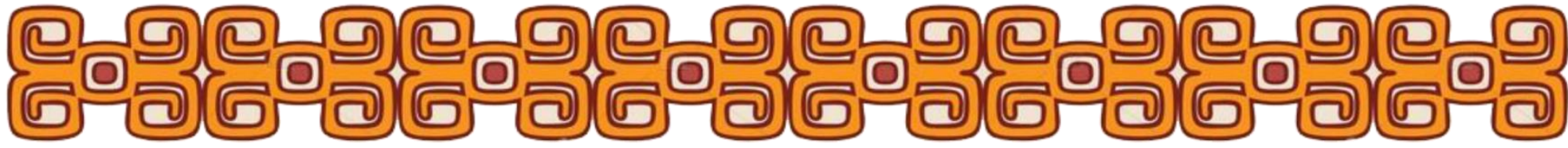

\section{REFERÊNCIAS}

BRASIL, Ministério da Educação, Secretaria de Educação Média e Tecnológica. Parâmetros Curriculares Nacionais: Ensino Médio. Brasília: MEC, 1997.

CALAZANS, Flávio. Gibis em sala de aula? Por que não? Entrevista publicada na revista Direcional Escolas - edição 11 - dezembro/2005.

CARDOSO, Beatriz, TEBEROSKY, Ana (Org.). Reflexões sobre o ensino da leitura e da escrita, $5^{a}$ Ed. - Campinas, SP. Editora da Universidade Estadual de Campinas; Petrópolis, RJ: Vozes, 1993.

COSTA, Jussara Brito. Leitura na Escola: resgatando o ato de ler através das tecnologias. (TCC- Especialização Mídias na Educação). UFRR. 2010.

EVANGELISTA, Aracy Alves Martins, BRANDÃO, Heliana Maria Brina, MACHADO, Maria Zélia Versiani (Org.). Escolarização da leitura literária $2^{a}$ Ed. Belo Horizonte: Autêntica 2001.

FRIGOTTO, Gaudêncio. Cidadania, tecnologia e trabalho. Desafios de uma escola renovada. Tecnologia Educacional. Rio de Janeiro, v. 21 nº 107, p. 04-10, jul/ago. 1992.

HIGINO, Anderson, BARBOSA, Clarisse, PEREIRA, Maria Antonieta (Org.). Formando leitores de telas e textos. Belo Horizonte: Linha editorial Tela e Texto, FALE/UFMG, 2007

LAJOLO, Marisa, ZILBERMAN, Regina. A formação da leitura no Brasil, $3^{\text {a }}$ edição, editora ática - São Paulo, 1996.

MORAN, José Manuel. Desafios na comunicação pessoal; Gerenciamento integrado da comunicação pessoal, social e tecnológica. $3^{\text {a }}$ ed., São Paulo, Paulinas, 2007.

OLIVEIRA, Maria Cristina Xavier de. A arte dos quadrinhos e o literário. São Paulo, 2005. Tese de Doutorado. Universidade de São Paulo.

PAIS, Luiz Carlos. Educação escolar e as tecnologias da informática $-1^{\text {a }}$ ed. $1^{\text {a }}$. reimp. Belo Horizonte: Autêntica, 2005.

VERGUEIRO, Waldomiro (org.). 3.ed. Como usar as histórias em quadrinhos em sala de aula. São Paulo: Contexto, 2007.

VILLA, José Maria. V. Tem theses na globalization. In NETO, Maria I.D (Org). Social Development. Rio de Janeiro. UFRJ/EICOS/UNESCO, p. 133-159. 1995.

VYGOTSKY, Lev. S. Pensamento e Linguagem, SP: Martins Fontes, 1987.

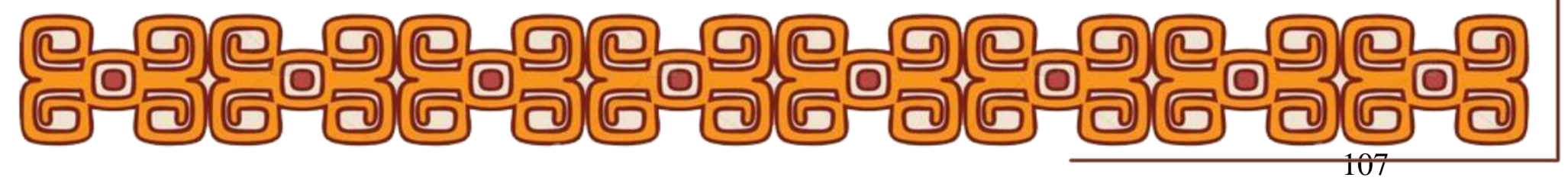

